Thorax, 1979, 34, 647-653

\title{
Chronic lung disease in the Papua New Guinea Highlands
}

\author{
H R ANDERSON
}

From the Papua New Guinea Institute of Medical Research

\begin{abstract}
In the Eastern Highlands of Papua New Guinea 46 men and 24 women with chronic lung disease underwent clinical and lung function investigations. In all cases the sole or predominant abnormality was irreversible airways obstruction, probably from chronic bronchitis with variable amounts of accompanying emphysema. There were close similarities to chronic obstructive lung disease in European populations in terms of symptoms, airways obstruction, transfer factor, and radiographic emphysema and inflammatory changes. Bronchiectasis and local fibrosis were present in a few subjects, but previous reports that pulmonary and pleural fibrosis are features of the disease were not confirmed. Possibly environmental and genetic factors may increase the associated blood gas disturbances leading to pulmonary hypertension. Unlike chronic obstructive lung disease in European populations, tobacco smoking is not an important aetiological factor. Although there is no direct evidence, the most likely possibilities are domestic wood smoke and acute chest infections.
\end{abstract}

In the Highlands of Papua New Guinea (PNG) several population surveys have reported a high prevalence of chronic respiratory symptoms and added chest sounds suggestive of chronic lung disease (CLD). These abnormalities become more common with age, affect men and women to a similar extent, and are associated with an obstructive ventilatory defect (Woolcock and Blackburn, 1967; Vines, 1970; Anderson, 1974a). Detailed studies by Woolcock et al (1970) concluded that although CLD was predominantly a chronic obstructive lung disease (COLD), it differed from that seen in European populations in having no lung overinflation, greater blood gas disturbance in relation to impairment of expiratory flows, and a later onset of dyspnoea. The pathological basis was thought to be chronic bronchitis and emphysema with extensive fibrosis of the lungs and pleura, and this was supported by necropsy evidence from two Highland lungs.

The apparent importance of fibrosis has encouraged the theory that CLD is probably the result of acute chest infections. The possibility of a chronic allergic alveolitis due to mould sensitivity has also been raised (Blackburn and Green, 1966; Blackburn and Woolcock, 1971). Pulmonary tuberculosis is absent or rare in most highland populations (Wigley, 1973). By analogy with
COLD in European populations, inhaled pollutants such as tobacco smoke and domestic wood smoke have also been suspected. The three population surveys cited above, however, found no relation between CLD and tobacco smoking, and direct evidence concerning the role of domestic wood smoke remains to be obtained. Knowledge of the pathological basis of CLD is important for further research into cause and for rational clinical management, but since necropsies are difficult to obtain it is necessary to rely on clinical investigations. The purpose of the present study was to extend available information about the clinical characteristics of highland CLD by using different methods of investigation in a larger and more severely affected group of subjects. The study took place at Goroka Hospital in the Eastern Highlands Province. The people of this area live at an altitude of $1500-2000 \mathrm{~m}$ and their characteristics and medical background have been described elsewhere (Hornabrook et al, 1974; Walsh, 1974).

\section{Methods}

The criteria for inclusion in the CLD study were chronic symptoms of cough or shortness of breath on exertion, added chest sounds of any kind unassociated with evidence of recent chest infec- 
tion, and right heart failure. Subjects whose main complaint was episodic wheezing were classified as asthma, and these are described elsewhere (Anderson, 1974b). The 70 CLD subjects were obtained in several ways: 35 had presented to hospital with respiratory symptoms or cardiac failure; a smaller group (13) had presented to hospital with nonrespiratory illness and chronic lung disease had been observed incidentally; and the remainder had been invited to come for investigation after identification during village surveys (17) or were relatives of hospital patients screened in the same way (5). If appropriate, investigations were postponed until chest infections or cardiac failure were controlled. In this stable period a structured questionnaire (using an interpreter) and physical examination were carried out. The forced expiratory volume in one second $\left(\mathrm{FEV}_{1}\right)$ and forced vital capacity (FVC) were measured with a McDermott portable spirometer. With a Resparameter (Meade et al, 1965) the total lung capacity (TLC), functional residual capacity (FRC), and residual volume $(R V)$ were measured by the steady state helium method, and the transfer factor (T1) was measured by the single breath method. The mixed venous carbon dioxide tension $\left(\mathrm{P}_{\overline{\mathrm{v}}} \mathrm{CO}_{2}\right)$ was estimated by the rebreathing method of Campbell and Howell (1962). After these tests the response of the $\mathrm{FEV}_{1}$ to inhaled salbutamol was measured.

Standard posteroanterior and right lateral chest radiographs were obtained and examined by an independent radiologist without clinical details or knowledge of the nature of lung disease in Papua New Guinea. The diaphragm was described as "low" if on the right side it was at or below the level of the 7th rib anteriorly, and "flat" if its dome was less than $1.5 \mathrm{~cm}$ above a line drawn between the costophrenic and cardiophrenic angles. A low or low-flat diaphragm was regarded as evidence of hyperinflation. The radiographic diagnosis of emphysema required a low-flat diaphragm plus narrowing or loss of pulmonary vessels (Simon, 1971). Streaky shadows, with or without lobar shrinkage, were regarded as evidence of lung destruction or fibrosis, and dilated bronchi associated with patchy shadows or lobar shrinkage as evidence of bronchiectasis. Bronchograms were performed on eight patients by injecting an oily contrast medium ("Dyonosil oily") through the cricothyroid membrane after suitable local anaesthesia. The electrocardiograph was examined for evidence of right ventricular hypertrophy and pulmonary heart disease using the criteria of Rees et al (1964).

Sera from 33 CLD subjects and 11 subjects over the age of 35 years without evidence of respiratory disease (relatives of patients or patients with minor non-respiratory illness) were examined for Haemophilus influenzae-specific $\left(\mathrm{H}_{1}\right)$ antibodies. $\mathrm{Cu}-\frac{\sigma}{\sigma}$

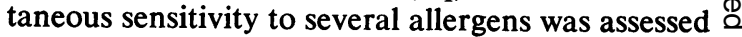
by the prick test and compared with the results \& of village surveys (Anderson, 1974b). Haemoglobin $\vec{\circ}$ (Hb) levels were compared with those reported for a nearby population (Crane et al, 1972). Reference $\vec{\omega}$ values for $\mathrm{FEV}_{1}, \mathrm{FVC}$, and $\mathrm{FEV}_{1} / \mathrm{FVC} \%$ were obtained from whole population data (Anderson $\vec{x}$ et $a l, 1974)$, and reference values for the other $\omega$ lung function tests were based on data from 45 ir men and 35 women described elsewhere (Cotes et $a l, 1974)$. Standardisation for age and stature was done by expressing results as a percentage of pre- 윽 dicted. For most tabulations, subjects were divided into severe $\left(\mathrm{FEV}_{1}<50 \%\right.$ predicted) and less severe $\left(\mathrm{FEV}_{1} \geqslant 50 \%\right.$ predicted) categories.

\section{Results}

The mode of presentation, history, and physical findings are shown in table 1 . The ratio of men to women was $2: 1$, and most subjects were under

Table 1 History and physical findings during a stable period in 70 subjects with chronic lung disease

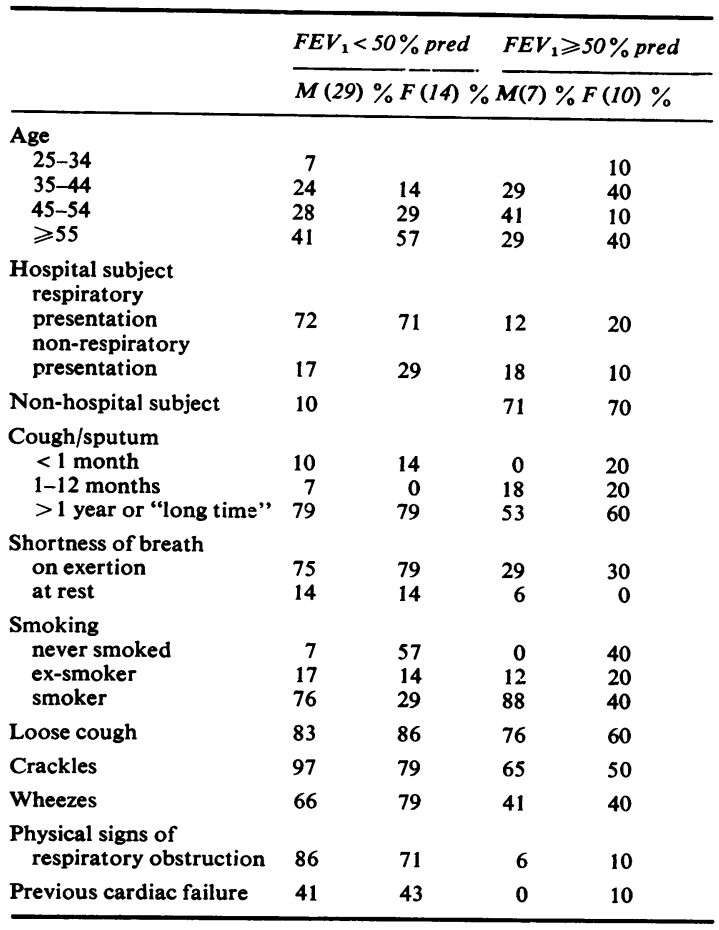


the age of 55 years. Shortness of breath had usually been preceded by chronic productive cough and was often of a wheezing character brought on not only by exertion but by coughing bouts and acute chest infections (increasing cough with purulent sputum and fever). Crepitations (crackles) tended not to clear completely with coughing, were medium or coarse rather than fine in character, and were often heard in both expiratory and inspiratory phases of respiration. Rhonchi (musical or wheezing sounds), which were observed in fewer patients, were usually low pitched and scattered and tended to clear with coughing; however, a few subjects had generalised high pitched rhonchi that varied from day to day. An audible productive or "loose" cough was elicited in most subjects. Physical signs of respiratory obstruction were observed in most of the severe group; these included contraction of sternomastoid and scalene muscles on inspiration, tracheal tug, abdominal 'respiration, and indrawing of supraclavicular spaces and intercostal muscles on inspiration. Right heart failure (defined as raised jugular venous pressure with peripheral oedema) had been present on admission or on a prior occasion in about $40 \%$ of the severe group.

The radiographic findings are shown in table 2 .

Table 2 Chest radiograph and electrocardiogram of subjects with chronic lung disease

\begin{tabular}{|c|c|c|c|c|}
\hline \multirow[b]{3}{*}{ Chest radiograph $(n)$} & \multirow{3}{*}{$\begin{array}{l}\begin{array}{l}F E V_{1} \\
\geqslant 50 \% \\
\text { pred }\end{array} \\
\\
\begin{array}{l}(20) \\
\%\end{array}\end{array}$} & \multicolumn{3}{|c|}{$F E V_{1}<50 \%$ predicted } \\
\hline & & \multirow[b]{2}{*}{$\begin{array}{l}\text { All (42) } \\
\%\end{array}$} & \multicolumn{2}{|c|}{$\begin{array}{l}\text { Previous cardiac } \\
\text { failure }\end{array}$} \\
\hline & & & $\begin{array}{l}\text { No }(24) \\
\%\end{array}$ & $\begin{array}{l}\text { Yes }(18) \\
\%\end{array}$ \\
\hline Normal radiograph & 55 & 14 & 25 & 0 \\
\hline $\begin{array}{l}\text { Low diaphragm } \\
\text { Low-flat diaphragm } \\
\text { Hyperinflation (low +low- } \\
\text { flat) }\end{array}$ & $\begin{array}{l}20 \\
10 \\
30\end{array}$ & $\begin{array}{l}26 \\
31\end{array}$ & $\begin{array}{l}17 \\
50 \\
67\end{array}$ & $\begin{array}{r}39 \\
6 \\
44\end{array}$ \\
\hline $\begin{array}{l}\text { Local emphysema } \\
\text { Widespread emphysema } \\
\text { All emphysema }\end{array}$ & $\begin{array}{r}10 \\
0 \\
10\end{array}$ & $\begin{array}{r}21 \\
7 \\
29\end{array}$ & $\begin{array}{l}33 \\
13 \\
46\end{array}$ & $\begin{array}{l}6 \\
0 \\
6\end{array}$ \\
\hline $\begin{array}{l}\text { Acute or chronic } \\
\text { inflammatory changes } \\
\text { Effusions } \\
\text { Blood diversion }\end{array}$ & $\begin{array}{r}15 \\
0 \\
15\end{array}$ & $\begin{array}{l}26 \\
21 \\
48\end{array}$ & $\begin{array}{r}21 \\
0 \\
38\end{array}$ & $\begin{array}{l}33 \\
50 \\
61\end{array}$ \\
\hline $\begin{array}{l}\text { Prominent pulmonary } \\
\text { conus }\end{array}$ & 10 & 52 & 21 & 94 \\
\hline $\begin{array}{l}\text { Mean cardiac diameter }(\mathrm{cm} \\
\text { Male } \\
\text { Female }\end{array}$ & $\begin{array}{l}12 \cdot 9 \\
13 \cdot 2\end{array}$ & $\begin{array}{l}13 \cdot 4 \\
13 \cdot 2\end{array}$ & $\begin{array}{l}12 \cdot 8 \\
11 \cdot 9\end{array}$ & $\begin{array}{l}14 \cdot 3 \\
14 \cdot 5\end{array}$ \\
\hline Electrocardiogram $(n)$ & $(22) \%$ & $(42) \%$ & $(24) \%$ & $(17) \%$ \\
\hline $\begin{array}{l}\text { Right ventricular } \\
\text { hypertrophy } \\
\text { Pulmonary heart disease } \\
\text { T wave inversion } V_{1-3} \\
\text { Other abnormalities }\end{array}$ & $\begin{array}{r}5 \\
5 \\
18 \\
0\end{array}$ & $\begin{array}{l}38 \\
10 \\
48 \\
12\end{array}$ & $\begin{array}{r}17 \\
8 \\
29 \\
8\end{array}$ & $\begin{array}{l}67 \\
11 \\
72 \\
17\end{array}$ \\
\hline
\end{tabular}

Evidence of hyperinflation was common and was the predominant abnormality in the less severe group. Emphysema was most often observed in men of the severe group. Inflammatory changes in the severe group consisted of: local fibrosis and shrinkage (two); lower lobe bronchiectasis (three); right middle lobe bronchiectasis (one); fine nodular appearance in lower zones (one); patchy changes suggestive of acute inflammation (three); and unilateral hypertransradiancy with small pulmonary artery (one). The inflammatory changes observed in three of the less severe group were all confined to the right middle lobe or lingula. None had extensive pleural shadowing and pleural effusions were small. Of four severe cases undergoing bronchography, two showed bronchiectasis and two showed bronchi of normal calibre but with abnormal peripheral filling. Of the four less severe cases, two were normal, one showed peripheral non-filling with "peripheral pools," and one showed bronchiectasis. Peripheral non-filling was thought to indicate mucus obstruction or organic occlusion rather than insufficient contrast medium. Electrocardiographic evidence of right ventricular hypertrophy was confined to the severe group with one exception $\left(\mathrm{FEV}_{1} 52 \%\right.$ predicted) and was more common in those with previous cardiac failure $(67 \%)$ than in those without $(17 \%)$. "Other abnormalities" consisted of four subjects in the severe group with $Q$ waves extending from $V_{1}$ to $V_{4}$ or beyond, and one who had the pattern of an old inferior myocardial infarction. Inverted $T$ waves $V_{1}-V_{3}$ were common and sometimes reversible.

The results of the lung function tests are shown in table 3. On the basis of the $\mathrm{FEV}_{1} / \mathrm{VC} \%$, all subjects in the severe group had an obstructive lung function defect, the highest value being $56 \%$. In this group the mean change in $\mathrm{FEV}_{1}$ after salbutamol inhalation was $0.111(0-0.4)$ in men and $0.171(0-0.4)$ in women. Among the less severe group, an obstructive pattern was also observed and among those with an $\mathrm{FEV}_{1}$ of $50-74 \%$ predicted, the mean change of $\mathrm{FEV}_{1}$ with salbutamol was $0.121(0-0.29)$. The 17 subjects whose $\mathrm{FEV}_{1}$ was within the normal range $(>75 \%$ predicted) had mean values for $\mathrm{FEV}_{1} / \mathrm{VC} \%$ and $\mathrm{RV}$ of $91 \%$ and $116 \%$ predicted, respectively.

Measurements of $\mathbf{P} \bar{v} \mathrm{CO}_{2}$ were obtained in 22 of the 43 severe subjects. The mean value was $7 \cdot 3$ $\mathrm{kPa}$ (range 5.3-9.3) and all but one was above $6.0 \mathrm{kPa}$ (estimated upper limit of normal at this altitude). In severely affected men and women of both groups the $\mathrm{Hb}$ level was at least $2 \mathrm{~g} \%$ above that predicted for the general population. 
Table 3 Lung function values of highland subjects with chronic lung disease

\begin{tabular}{|c|c|c|c|c|c|c|c|c|}
\hline & \multicolumn{4}{|l|}{ Men } & \multicolumn{4}{|c|}{ Women } \\
\hline & \multicolumn{2}{|c|}{$\begin{array}{l}F E V_{1} \geqslant 50 \% \text { predicted } \\
I 7(I 1)^{*}\end{array}$} & \multicolumn{2}{|c|}{$\begin{array}{l}F E V_{1}<50 \% \text { predicted } \\
29(17)\end{array}$} & \multicolumn{2}{|c|}{$\begin{array}{l}F E V_{1} \geqslant 50 \% \text { predicted } \\
10(6)\end{array}$} & \multicolumn{2}{|c|}{$\begin{array}{l}F E V_{1}<50 \% \text { predicted } \\
14(2)\end{array}$} \\
\hline & Mean & Range & Mean & Range & Mean & Range & Mean & Range \\
\hline $\begin{array}{l}\text { Age (yr) } \\
\mathrm{Hb}_{(\mathrm{g} \%} \% \\
\mathrm{FEV}_{1}(\% \text { pred }) \\
\mathrm{FEV}_{1} / \mathrm{VC} \% \\
\mathrm{FEV}_{1} / \mathrm{VC} \%(\% \text { pred }) \\
\text { VC }(\% \text { pred }) \\
\text { TLC }(\% \text { pred) } \\
\text { RV }(\% \text { pred) } \\
\text { RV/TLC } \% \\
\text { RV/TLC } \%(\% \text { pred }) \\
\text { T1 (\% pred) }\end{array}$ & $\begin{array}{l}48 \\
15 \cdot 1 \\
84 \\
60 \cdot 2 \\
80 \\
101 \\
101 \\
118 \\
40 \cdot 1 \\
116 \\
91\end{array}$ & $\begin{array}{l}35-60 \\
12 \cdot 0-17 \cdot 5 \\
54-116 \\
43 \cdot 5-83 \cdot 7 \\
60-113 \\
60-124 \\
86-114 \\
91-152 \\
28 \cdot 7-61 \cdot 7 \\
86-165 \\
63-113\end{array}$ & $\begin{array}{l}48 \\
17 \cdot 4 \\
31 \\
34 \cdot 0 \\
46 \\
66 \\
95 \\
165 \\
59 \cdot 0 \\
174 \\
83\end{array}$ & $\begin{array}{l}27-75 \\
10 \cdot 7-21 \cdot 2 \\
11-48 \\
21 \cdot 9-52 \cdot 9 \\
28-73 \\
35-100 \\
68-121 \\
93-311 \\
43 \cdot 1-75 \cdot 5 \\
131-303 \\
58-115\end{array}$ & $\begin{array}{l}50 \\
15 \cdot 6 \\
85 \\
66 \cdot 3 \\
89 \\
90 \\
93 \\
107 \\
42 \cdot 1 \\
115 \\
110\end{array}$ & $\begin{array}{l}33-65 \\
13 \cdot 4-20 \cdot 0 \\
52-129 \\
46 \cdot 6-84 \cdot 8 \\
67-112 \\
60-118 \\
70-113 \\
83-141 \\
28 \cdot 0-60 \cdot 7 \\
97-139 \\
86-168\end{array}$ & $\begin{array}{l}52 \\
16 \cdot 3 \\
40 \\
43 \cdot 4 \\
59 \\
67 \\
93 \\
145 \\
60 \cdot 0 \\
159 \\
64\end{array}$ & $\begin{array}{l}40-60 \\
14 \cdot 3-22 \cdot 1 \\
20-49 \\
21 \cdot 7-56 \cdot 1 \\
28-76 \\
41-91 \\
75-113 \\
125-181 \\
48 \cdot 5-75 \cdot 0 \\
141-183 \\
54-74\end{array}$ \\
\hline
\end{tabular}

*Number with transfer factor measurement.

Among the whole group of 70 subjects, four men and two women had values of TLC of less than $75 \%$ predicted (lowest value was $68 \%$ predicted) and for this reason might be considered to have had a significant degree of restriction. Although values for the T1 obtained in three of this group were all reduced (range $59-66 \%$ predicted) the diffusing capacity per unit lung volume (KCO) was above $90 \%$ in each case. None of these six cases had radiographic evidence of local or diffuse fibrosis; their radiographic abnormalities were: right middle lobe bronchiectasis (one), limited emphysema (two), low diaphragm (one), unilateral effusion (one), and normal film (two).

On average, the $\mathrm{T} 1$ was lower in those with radiographic evidence of emphysema (77\% predicted) than in those without ( $92 \%$ predicted). None of the three subjects with a T1 of less than $60 \%$ predicted had radiographic evidence of pulmonary fibrosis.

Within the severe group, subjects with past cardiac failure were, on average, six years older and had higher values for $\mathrm{P}_{\overline{\mathrm{v}}} \mathrm{CO}_{2}(8 \cdot 2 \mathrm{kPa})$ than those without $(7 \cdot 0 \mathrm{kPa})$. They also tended to have lower lung volumes and transfer factor though these differences were not pronounced and the FEV/ $\mathrm{VC} \%$ was similar in both groups.

Reactions of $3 \mathrm{~mm}$ or more to prick testing with a number of allergens were observed in 5/19 (26\%) of less severe and 7/30 (23\%) of severe subjects; these rates did not differ significantly from those observed in 122 highland village adults. $H$ influenzae $\left(\mathrm{H}_{1}\right)$ antibodies were significantly more common in patients $(12 / 33)$ than in hospital controls $(0 / 11)$.

\section{Discussion}

In all subjects investigated the sole or predominant lung function abnormality was one of chronic airways obstruction. This suggests that the main cause of chronic productive cough in this community is chronic bronchitis. The evidence of the chest radiograph and transfer factor suggests that a proportion of subjects also had emphysema (Thurlbeck et al, 1970; Hugh-Jones and Whimster, 1978). These findings are supported by the limited amount of available pathological data (Woolcock et al, 1970; Cooke and Toogood, 1975). While the less severe group was likely to be reasonably representative of CLD at the village level, the more severe group may have been biased towards those types of chronic lung disease that are more liable to infective complications and cardiac failure. For this reason, chronic bronchitis may have been over-estimated in relation to emphysema.

There is little doubt that a minority of cases had local pulmonary fibrosis or bronchiectasis and that the latter might have been underestimated from the plain chest radiograph. The present radiographic evidence, however, does not support the conclusion of Woolcock et al (1970) that extensive pulmonary and pleural fibrosis is a feature of CLD. Furthermore, a restrictive lung function component was not prominent, and none of those with relatively low values for the TLC had evidence of lung fibrosis or reduction in Kco.

All subjects with a history of episodic wheezc suggestive of asthma were excluded from this CLD series. About one-fifth of Highland asthmatics investigated, however, had additional symp- 
toms of chronic cough and might, for this reason, have been also classified as CLD. These cases were 12 years older at the onset of asthma (mean onset age 40) but otherwise resembled other asthmatics rather than the CLD group in terms of sensitivity to allergens ( $100 \%$ positive), sputum histology, and variability of $\mathrm{FEV}_{1}$ (Anderson, 1974b). Lung volumes were consistent with obstruction and the T1 was normal. Because asthma has a low prevalence in this area, it is unlikely that this overlapping category is important at a village level.

Highland CLD closely resembles the COLD of European countries in many respects. Compared with 100 patients from London and Chicago (Burrows et al, 1964) the 29 Highland men with severe CLD were similar in respect of airways obstruction $\left(\mathrm{FEV}_{1}, \quad \mathrm{FEV}_{1} / \mathrm{VC} \%, \mathrm{RV}, \mathrm{RV} / \mathrm{TLC} \%\right)$, chronic cough, dyspnoea on exertion, and radiographic evidence of inflammatory changes and emphysema. The frequency of radiographic emphysema (both widespread and limited) was also similar to that observed in a London series with similar degrees of airways obstruction and examined by the same radiologist using the same criteria (Simon et al, 1973). The Highlanders differed from the London and Chicago group in having a normal rather than increased TLC and in having less reduction in $\mathrm{T} 1$; however, when corrected for differences in $\mathrm{Hb}$ by the method of Cotes et al (1972), the T1 was reduced to the level of the London and Chicago group. The frequency of $\mathrm{H}_{1}$ antibodies was similar to that observed in British patients with simple chronic bronchitis (Burns and May, 1967).

Compared with the European series, the Highland subjects had higher levels of $\mathrm{Hb}$ and $\mathrm{P}_{\overline{\mathrm{V}} \mathrm{CO}_{2}}$ (allowing for altitude), and a higher proportion had an enlarged heart, cardiac failure, and electrocardiographic evidence of right ventricular hypertrophy. Although these differences might be explained by selection, the blood gas results are supported by the finding of Woolcock et al (1970) among less selected and less severe subjects with CLD, that blood gas disturbances were greater than expected from the reduction in expiratory flows. This might be due to: (1) a reduced ventilatory response to $\mathrm{CO}_{2}$ that has been shown in healthy highlanders and coastal dwellers and which is believed to be genetically determined (Beral and Read, 1971; Patrick and Cotes, 1974) or (2) a reduced ventilatory response to hypoxia that is known to occur in Andean Indians reared at $2300 \mathrm{~m}$ (Sørenson and Severinghaus, 1968) and which might be relevant at the slightly lower altitude of the PNG Highlands or both. Considering also the effect of hypoxia of altitude (normal $\mathrm{PaO}_{2}$ at $1600 \mathrm{~m}$ is about $10 \mathrm{kPa}$ ), it appears that highlanders with CLD would be likely to develop pulmonary hypertension and right heart failure at an earlier stage of the disease. This may explain the relatively younger age of the Highland subjects compared with the European group.

In view of the aetiological importance of inhaled pollutants in European COLD, a similar mechanism would also seem likely in the Highland context. Although the smoking of home grown tobacco is common in this area, however, epidemiological studies have failed to show any relation to obstructive lung disease (Woolcock and Blackburn, 1967; Vines, 1970; Anderson, 1974a) and the distribution of smoking habits among the present 70 subjects did not differ from those expected in the general population. The other main inhaled pollutant, one to which the entire population is exposed every night, is domestic wood smoke (Cleary and Blackburn, 1968; Anderson, 1974a), but this has been difficult to implicate directly because of the absence of non-exposed Highlanders with whom comparisons could be made.

Vines (1970) and Woolcock et al (1970) have both suggested that the main cause of CLD may be repeated or severe chest infections. The present study supports this theory in so far as some subjects were found to have local lung fibrosis and bronchiectasis that had presumably resulted from acute infections, possibly in early life. Most subjects, however, had no such evidence of past lung damage, and the proportion with "inflammatory changes" was no greater than in European COLD. There is limited evidence from European populations that childhood chest infections may act in a more subtle manner by sensitising the airways to the effects of inhaled pollutants (Colley et al, 1973; Burrows et al, 1977). Such an association, if established in European populations, would clearly be relevant to Highland CLD.

It has been speculated that Highland CLD might be at least partly due to a chronic allergic alveolitis similar to farmer's lung (Blackburn and Green, 1966; Blackburn and Woolcock, 1971). Notwithstanding the fact that farmer's lung may lead to obstructive lung disease and radiographic emphysema (Hapke et al, 1968), such a process would seem an unlikely cause of CLD in view of the absence of the other clinical, functional, and radiological features of the farmer's lung spectrum.

I wish to record my gratitude to the late Dr George Simon for examining the chest radiographs, to $\mathrm{Dr}$ A J Thomas for examining the electrocardio- 
graphs, and to Dr C Clarke for the haemophilus precipitins testing. The project was originally conceived by Dr J E Cotes who gave advice and support throughout. The author was under secondment from the Papua New Guinea Department of Public Health to the Papua New Guinea Institute of Medical Research. Financial assistance was received from the Australian Academy of Science as part of the International Biological Programme. Finally, I am indebted to the MRC Pneumoconiosis Unit, Penarth, UK, for providing the facilities for analysis of these data, and in particular to Mr G Berry for advice about analysis.

\section{References}

Anderson, H R (1974a). The prevalence and nature of chronic lung disease and asthma in highland Papua New Guinea. MD Thesis, Melbourne University.

Anderson, H R (1974b). The epidemiological and allergic features of asthma in the New Guinea Highlands. Clinical Allergy, 4, 171-183.

Anderson, H R, Anderson, J A, and Cotes, J E (1974). Lung function values in healthy children and adults from highland and coastal areas of Papua New Guinea: prediction nomograms for forced expiratory volume and forced vital capacity. Papua New Guinea Medical Journal, 17, 165-167.

Beral, V, and Read, D J C (1971). Insensitivity of respiratory centre to carbon dioxide in the Enga people of New Guinea. Lancet, 2, 1290-1294.

Blackburn, C R B, and Green, W (1966). Precipitins against extracts of thatched roofs in the sera of New Guinea natives with chronic lung disease. Lancet, 2, 1396-1397.

Blackburn, C R B, and Woolcock, A J (1971). Chronic disease of liver and lungs in New Guinea. Journal of the Royal College of Physicians, 5, 241-249.

Burns, M W, and May, J R (1967). Haemophilus influenzae precipitins in the serum of patients with chronic bronchial disorders. Lancet, 1, 354-358.

Burrows, B, Knudson, R J, and Lebowitz, M D (1977). The relationship of childhood respiratory illness to adult obstructive airway disease. American Review of Respiratory Disease, 115, 751-760.

Burrows, B, Niden, A H, Fletcher, C M, and Jones, N L (1964). Clinical types of chronic obstructive lung disease in London and Chicago: a study of one hundred patients. American Review of Respiratory Disease, 90, 14-27.

Campbell, E J M, and Howell, J B L (1962). Rebreathing method for measurement of mixed venous $\mathrm{PCO}_{2}$. British Medical Journal, 2, 630-633.

Cleary, G J, and Blackburn, C R B (1968). Air pollution in native huts in the highlands of New Guinea. Archives of Environmental Health, 17, 785-794.

Colley, J R T, Douglas, J W B, and Reid, D D (1973). Respiratory disease in young adults: influence of early childhood lower respiratory tract illness, social class, air pollution, and smoking. British Medical $\stackrel{\vec{F}}{\stackrel{\vec{S}}{\circ}}$ Journal, 3, 195-198.

Cooke, R, and Toogood, I (1975). Emphysema in 흠 Papua New Quinea: a pathological study. Australian $\frac{\bar{S}}{\partial}$ and New Zealand Journal of Medicine, 5, 147-154. $\stackrel{\mathbb{Q}}{\AA}$

Cotes, J E, Anderson, H R, and Patrick, J M (1974). Lung function and the response to exercise in native New Guineans: role of genetic and environmental $\vec{\circ}$ factors. Philosophical Transactions of the Royal $\overrightarrow{\vec{\omega}}$ Society, London, Series B., 268, 349-361.

Cotes, J E, Dabbs, J M, Elwood, P C, Hall, A M, McDonald, A, and Saunders, M J (1972). Iron- $x$ deficiency anaemia: its effect on transfer factor for $\stackrel{\omega}{\omega}$ the lung (diffusing capacity) and ventilation ander cardiac frequency during sub-maximal exercise.
Clinical Science, 42, 325-335.

Crane, G G, Hornabrook, R W, and Kelly, A (1972).을 Anaemia on the coast and highlands of New Guinea. Human Biology in Oceania, 1, 234-241.

Hapke, E J, Seal, R M E, Thomas, G O, Hayes, M, and Meek, J C (1968). Farmer's lung: a clinical, radiographic, functional, and serological correlation $\frac{\mathbb{}}{-}$ of acute and chronic stages. Thorax, 23, 451-468.

Hornabrook, R W, Crane, G G, and Stanhope, J M (1974). Karkar and Lufa. An epidemiological and. health background to the human adaptability studies of the International Biological Programme. Philo-s sophical Transactions of the Royal Society, London, Series B, 268, 293-308.

Hugh-Jones, P, and Whimster, W (1978). The etiology and management of disabling emphysema. American Review of Respiratory Disease, 117, 343-378.

Meade, F, Saunders, M J, Hyett, F, Reynolds, J A, Pearl, N, and Cotes, J E (1965). Automatic measurement of lung function. Lancet, 2, 573-575.

Patrick, J M, and Cotes, J E (1974). Anthropometric and other factors affecting respiratory responses to음 $\mathrm{CO}_{2}$ in New Guinea. Philosophical Transactions of $\underset{\times}{\times}$ the Royal Society, London, Series B, 268, 363-373. 음

Rees, H A, Thomas, A J, and Rossiter, C (1964). The recognition of coronary heart disease in the presence of pulmonary disease. British Heart Journal, 26, 233-240. 26, 233-240.
3rd edn. Butterworth, London.

Simon, G, Pride, N B, Jones, N L, and Raimondi, A C (1973). Relation between abnormalities in the $N$ chest radiograph and changes in pulmonary function in chronic bronchitis and emphysema. Thorax, 28,

Sørenson, S C, and Severinghaus, J W (1968). Irre-O versible respiratory insensitivity to acute hypoxia ino man born at high altitude. Journal of Applied ${ }_{\overparen{\varnothing}}$ Physiology, 25, 217-220.

Thurlbeck, W M, Henderson, J A M, Fraser, R G, and Bates, D V (1970). Chronic obstructive lung disease: A comparison between clinical, roentgen- $\frac{\vec{\Phi}}{\mathrm{D}}$ ologic, functional, and morphologic criteria in $\frac{\mathrm{P}}{\mathbb{D}}$ chronic bronchitis, emphysema, asthma and bron- $\mathbb{Q}$ chiectasis. Medicine, 49, 81-145.

Vines, A P (1970). An Epidemiological Sample Survey 
of the Highland, Mainland and Island Regions of the Territory of Papua and New Guinea. Department of Public Health, Port Moresby.

Walsh, R J (1974). Geographical, historical and social background of the peoples studied in the International Biological Programme. Philosophical Transactions of the Royal Society, London, Series B, 268, 223-228.

Wigley, S C (1973). Tuberculosis. In The Diseases and Health Services of Papua New Guinea, edited by C Bell, p 179. Department of Public Health, Port Moresby.

Woolcock, A J, and Blackburn, C R B (1967). Chronic lung disease in the territory of Papua and New
Guinea: An epidemiological study. Australasian Annals of Medicine, 16, 11-19.

Woolcock, A J, Blackburn, C R B, Freeman, M H, Zylstra, W, and Spring, S R (1970). Studies of chronic (non-tuberculous) lung disease in New Guinea populations. The nature of the disease. American Review of Respiratory Disease, 102, 575-589.

Requests for reprints to: Dr H R Anderson, Department of Clinical Epidemiology and Social Medicine, St George's Hospital Medical School, Cranmer Terrace, London SW17 0RE. 